\title{
Concerns for labor analgesia and autism spectrum disorders
}

\author{
Manabu Saito $^{1}\left[\right.$ Kazuhiko Nakamura ${ }^{1} \cdot$ Kazuyoshi Hirota $^{2}$ \\ Received: 3 November 2020 / Accepted: 7 November 2020 / Published online: 24 November 2020 \\ (c) The Author(s) 2020
}

Keywords Labor epidural analgesia $\cdot$ Autism spectrum disorders $\cdot$ Hazard ratio

\section{To the Editor:}

We read with great interest the Association between Epidural Analgesia during Labor and Risk of Autism Spectrum Disorders in Offspring by Chunyuan Qiu et al. published in JAMA Pediatrics on October 12, 2020 [1]. The findings were that in this multiethnic population-based clinical birth cohort that included 147,895 children, Autism spectrum disorders (ASD) were diagnosed in $1.9 \%$ of the children delivered vaginally with labor epidural analgesia (LEA) vs. $1.3 \%$ without the exposure, $37 \%$ relative increase in risk that was significant after adjusting for potential confounders. We appreciate the authors' efforts, however, we have some concerns in this study as ASD specialists [2].

First of all, they used Cox proportional hazards regression analysis to estimate the hazard ratio (HR) of ASD associated with LEA exposure, but as described in the limitation, it cannot be interpreted as a causal relationship. Because they do not consider other risk factors in previous reports as covariates that affect outcomes. For example, the information of ASD diagnosis in parents is needed given that autism is currently estimated to be $40-80 \%$ genetic. In addition, information such as viral infections or exposure to air pollution during pregnancy and perinatal hypoxic encephalopathy should be needed as non-genetic factors of ASD. They should show that LEA exposure is one of the hundreds of environmental factors for ASD.

Second, the main outcome is the clinical diagnosis of ASD, but the basis for the diagnosis is unclear and no other

Manabu Saito

smanabu@hirosaki-u.ac.jp

1 Department of Neuropsychiatry, Graduate School of Medicine, Hirosaki University, 5 Zaifu-cho, Hirosaki 036-8562, Japan

2 Department of Anesthesiology, Graduate School of Medicine, Hirosaki University, 5 Zaifu-cho, Hirosaki 036-8562, Japan comorbidities (such as ADHD) have been identified, it cannot be determined whether the outcome ASD diagnosis is reliable. In addition, the sample ratio is 3:1, and the effect of the number of samples on detection power cannot be denied. Further verification is needed on the association between LEA and ASD. Therefore, the hazard rate associated with LEA could be an error.

The final concern is the impact of this title on mothers who choose LEA. Some of the mothers may feel anxious and guilty. Although it is clearly stated in the paper that there is no causal relationship, it is difficult to read that point from the title and abstract. We strongly hope that many people will be able to accurately understand the interpretation of this research result as LEA is getting popular in Japan [3].

\section{Compliance with ethical standards}

Conflict of interest None declared.

Open Access This article is licensed under a Creative Commons Attribution 4.0 International License, which permits use, sharing, adaptation, distribution and reproduction in any medium or format, as long as you give appropriate credit to the original author(s) and the source, provide a link to the Creative Commons licence, and indicate if changes were made. The images or other third party material in this article are included in the article's Creative Commons licence, unless indicated otherwise in a credit line to the material. If material is not included in the article's Creative Commons licence and your intended use is not permitted by statutory regulation or exceeds the permitted use, you will need to obtain permission directly from the copyright holder. To view a copy of this licence, visit http://creativecommons.org/licenses/by/4.0/.

\section{References}

1. Chunyuan Qiu, Jane C. Lin, Jiaxiao M. Shi, Ting Chow, Vimal N. Desai, Vu T. Nguyen, Robert J. Riewerts, R. Klara Feldman, Scott Segal, Anny H. Xiang. Association between epidural analgesia during labor and risk of autism spectrum disorders in offspring. 
JAMA Pediatr. https://doi.org/10.1001/jamapediatrics.2020.3231. Published online October 12, 2020.

2. Saito M, Hirota T, Sakamoto Y, Adachi M, Takahashi M, OsatoKaneda A, Kim YS, Leventhal B, Shui A, Kato S, Nakamura K. Prevalence and cumulative incidence of autism spectrum disorders and the patterns of co-occurring neurodevelopmental disorders in a total population sample of 5-year-old children. Mol Autism. 2020;11:35.

3. Fujita N, Cole NM, Nagasaka Y. Challenges and hurdles for patient safety in obstetric anesthesia in Japan. J Anesth. 2018;32:901-7.
Publisher's Note Springer Nature remains neutral with regard to jurisdictional claims in published maps and institutional affiliations. 